\title{
AN EXPERIMENTAL INVESTIGATION OF VOLATILE EXSOLUTION IN EVOLVING MAGMA CHAMBERS
}

\author{
J. STEWART TURNER ${ }^{1}$, HERBERT E. HUPPERT ${ }^{2}$ and R. STEPHEN J. SPARKS ${ }^{3}$ \\ 'Research School of Earth Sciences, Australian National University, Canberra 2600 \\ (Australia) \\ ${ }^{2}$ Department of Applied Mathematics and Theoretical Physics, Cambridge University, \\ Cambridge (Great Britain) \\ ${ }^{3}$ Department of Earth Sciences, Cambridge University, Cambridge (Great Britain)
}

(Received March 25, 1982; revised and accepted September 11, 1982)

\section{ABSTRACT}

Turner, J.S., Huppert, H.E. and Sparks, R.S.J., 1983. An experimental investigation of volatile exsolution in evolving magma chambers. J. Volcanol. Geotherm. Res., 16: $263-277$.

Previous laboratory experiments investigating the fluid dynamics of replenished magma chambers have been extended to model effects resulting from the release of gas. Turbulent transfer of heat between a layer of dense, hot and volatile-rich mafic magma overlying cooler more evolved magma can lead to crystallization and exsolution of volatiles in the lower layer. Small gas bubbles can cause the bulk density to decrease to that of the upper layer and thus produce sudden overturning and initiate mixing, followed by further exsolution of gas and explosive eruption. These processes have been modelled in the laboratory using a chemical reaction between sodium or potassium carbonate and nitric acid to release small bubbles of $\mathrm{CO}_{2}$. We have investigated both the initial overturning produced by gas release in the lower layer, and the subsequent evolution of gas due to intimate mixing of the two layers. The latter experiments, in which the reactants remained isolated in the two layers until overturning occurred, demonstrated unambiguously that the fluxes of chemical components across the interfaces between convecting layers are very slow compared to the flux of heat. This shows that the evolution of layers of magma of different origins and composition can take place nearly independently of each other. The magmas can coexist in the same stratified chamber, until their bulk densities become equal and they mix together. The processes illustrated in these experiments could occur in $\mathrm{H}_{2} \mathrm{O}$ bearing magmas such as in the calcalkaline association and in $\mathrm{CO}_{2}$-bearing mafic magmas such as in silica undersaturated suites.

\section{INTRODUCTION}

During the last few years there has been an increasing interest in the fluid dynamics of evolving magma chambers. In order to understand the dynamics of phenomena such as magma chamber replenishment, magma mixing, the development of compositional stratification and volcanic activity, we feel 
that it is a necessary first step to develop models and experience with simple systems which have physical and chemical analogies to natural magmatic systems.

There are some fundamental properties of magmas which imply that they will behave in much more complex ways than was formerly conceived by petrologists. Magmas are multi-component and multi diffusive systems, and it is now clear that such systems display a wide range of interesting and novel convective behaviour not encountered in one-component systems (Huppert and Turner, 1981). In addition, the cooling of magma is characterised by crystallization and sometimes by exsolution of volatiles. The density changes associated with these two processes are found to be far larger than the corresponding density changes due to thermal effects (see for example McBirney and Noyes, 1979; Sparks et al., 1980; Huppert et al., 1982). Consequently, the evolution of magmatic systems will be strongly influenced by convective processes controlled by compositional variations or phase changes (for example, gas exsolution).

In the present paper we describe the results of experiments with aqueous solutions aimed at simulating some effects resulting from exsolution of volatiles. In developing our ideas leading to the current work we were influenced by the common occurrence of mixing in magmas of the calcalkaline association. There is evidence that such mixing often occurs just prior to eruption (Anderson, 1976; Sparks et al., 1977; Eichelberger, 1980) and arguments have been presented to suggest that the mafic component can be oversaturated in volatiles (Eichelberger, 1980; Huppert et al., 1982). This evidence led Huppert et al. (1982) to continue their earlier work (Huppert and Sparks, $1980 \mathrm{a}, \mathrm{b})$ and to propose a model in which volatile-bearing mafic magma is emplaced into a chamber containing more differentiated magma. The new influx of magma initially forms a lower layer which cools and crystallizes as it exchanges heat with the magma above. Volatile saturation followed by the release of volatiles occurs, and if the gas remains in suspension as small bubbles the lower layer can become equal in density to the upper layer and mix with it. In the investigation reported here we have experimentally modelled the release of gas in the lower layer using a chemical reaction, and have also investigated the effects of further release of gas when the lower layer fluid is rapidly quenched as it rises into and mixes with the colder fluid above it.

To facilitate comparison with past experiments using aqueous solutions, a brief outline of previous work is given at the beginning of the next section. We then describe in detail the new experiments and their results, and conclude with a discussion of the major findings of the experiments and their possible geological applications.

\section{THE LABORATORY EXPERIMENTS}

In the previous experiments described by Huppert and Turner (1981), which were designed to simulate replenishment of a magma chamber by hot, 
dense dry magma, we used aqueous solutions, the lower layer being hot $\mathrm{KNO}_{3}$ for which satured solutions become less dense as the temperature decreases. The upper, thicker layer was a cold solution of either $\mathrm{NaNO}_{3}$ or $\mathrm{K}_{2} \mathrm{CO}_{3}$, which was initially less dense than the lower layer. Strong convective transfer of heat took place through the sharp interface between the layers. After the temperature in the lower layer decreased sufficiently for it to become saturated, crystals grew in the lower layer, with the formation of less dense residual liquid. This caused more vigorous convection in the lower layer as well as being responsible for the decrease in density. When the densities of the two layers became equal, the interface suddenly broke down, mixing the two layers thoroughly together and leaving $\mathrm{KNO}_{3}$ crystals at the base (see the sequence of photographs presented by Huppert and Turner, 1981).

An important observation relevant to the present experiments is that during the early stages of the mixing of the two fluids there were strong, small-scale concentration fluctuations, made visible on a shadowgraph through their effect on refractive index. These persisted, throughout the experimental tank, much longer than detectable temperature fluctuations. Thus, until diffusion had had time to produce uniformity at the molecular level, smallscale compositional anomalies persisted after the temperature had equilibrated.

The experimental technique has now been extended to consider the behaviour of a similar system in which highly reactive components are present in the two layers. These two components are $\mathrm{HNO}_{3}$ and either $\mathrm{K}_{2} \mathrm{CO}_{3}$ or $\mathrm{Na}_{2} \mathrm{CO}_{3}$ which liberate $\mathrm{CO}_{2}$ bubbles on reaction. The experiments thus model the fluid dynamical effects of gas exsolution both before overturn and as a consequence of the small-scale mixing which follows overturn.

The experiments were performed in a Perspex container $(40 \times 20 \times 30 \mathrm{~cm}$ high) with the input fluid injected through a $0.7-\mathrm{cm}$ diameter orifice at the centre of the base, $0.7 \mathrm{~cm}$ above which there was an $8-\mathrm{cm}$ diameter disc in order to produce a smooth inflow. Thermistors were placed in the lower and upper layers at $4 \mathrm{~cm}$ and $9 \mathrm{~cm}$ above the bottom and the temperatures of the two layers monitored on a chart recorder. The motions were observed using the shadowgraph technique, and frequent colour photographs were taken. A number of cine films were also made, with sequences showing representative stages of the experiments.

Two different series of experiments were performed. Typical initial compositions of the upper and lower layers for each series are set out in Table I. The first series was undertaken to examine the overturning due to volatile release in the lower layer as it cools, which is the effect analysed theoretically by Huppert et al. (1982). The second series concentrated on the effects of mixing and further volatile release following overturning. We describe each series in turn, as well as some preliminary experiments which help in the interpretation of the later results.

In the first series, the upper layer fluid was a $23 \mathrm{wt} . \%^{*}$ aqueous $\mathrm{K}_{2} \mathrm{CO}_{3}$

* All such quantities cited in this section are nominal values. 
TABLE I

Typical chemical compositions of the two layers in the different experiments

\begin{tabular}{|c|c|c|c|c|c|c|}
\hline \multirow[b]{2}{*}{ Upper layer } & \multicolumn{2}{|c|}{ First series } & \multicolumn{2}{|c|}{ Second series } & \multicolumn{2}{|c|}{ Initial trials } \\
\hline & $\begin{array}{l}4.6 \mathrm{~kg} \\
15 \mathrm{l} \\
+\end{array}$ & $\begin{array}{l}\mathrm{K}_{2} \mathrm{CO}_{3} \\
\mathrm{H}_{2} \mathrm{O} \\
\mathrm{CO}_{2}\end{array}$ & $\begin{array}{l}8.0 \mathrm{~kg} \\
1.0 \mathrm{~kg} \\
16 \mathrm{l} \\
+\end{array}$ & $\begin{array}{l}\mathrm{NaNO}_{3} \\
\mathrm{Na}_{2} \mathrm{CO}_{3} \cdot 10 \mathrm{H}_{2} \mathrm{O} \\
\mathrm{H}_{2} \mathrm{O} \\
\mathrm{CO}_{2}\end{array}$ & $\begin{array}{l}5.0 \mathrm{~kg} \\
15 \mathrm{l} \\
+\end{array}$ & $\begin{array}{l}\mathrm{K}_{2} \mathrm{CO}_{3} \\
\mathrm{H}_{2} \mathrm{O} \\
\mathrm{CO}_{2}\end{array}$ \\
\hline Lower layer & $\begin{array}{l}2.2 \mathrm{~kg} \\
3.9 \mathrm{l} \\
+\mathrm{HNO}_{3}\end{array}$ & $\begin{array}{l}\mathrm{KNO}_{3} \\
\mathrm{H}_{2} \mathrm{O} \\
\text { after } 23 \mathrm{~min}\end{array}$ & $\begin{array}{l}2.9 \mathrm{~kg} \\
4.1 \mathrm{l} \\
300 \mathrm{~cm}^{3}\end{array}$ & $\begin{array}{l}\mathrm{KNO}_{3} \\
\mathrm{H}_{2} \mathrm{O} \\
\mathrm{HNO}_{3}\end{array}$ & $\begin{array}{l}3.8 \mathrm{~kg} \\
4.81 \\
300 \mathrm{~cm}^{3}\end{array}$ & $\begin{array}{l}\mathrm{KNO}_{3} \\
\mathrm{H}_{2} \mathrm{O} \\
\mathrm{HNO}_{3}\end{array}$ \\
\hline
\end{tabular}

solution at room temperature $\left(21^{\circ} \mathrm{C}\right)$ with a depth of $20 \mathrm{~cm}$. It was cooled in situ to $10^{\circ} \mathrm{C}$ by bubbling $\mathrm{CO}_{2}$ through it using dry ice held on the bottom of the tank by a wire gauze frame. This at the same time dissolved $\mathrm{CO}_{2}$ in the solution (though we did not measure how close it came to saturation). The specific gravity of the solution at the final temperature was approximately 1.230 . The lower layer fluid was a $36 \mathrm{wt}$.\% aqueous $\mathrm{KNO}_{3}$ solution plus $1 \mathrm{~cm}^{3}$ of blue dye. It was heated to $50^{\circ} \mathrm{C}$ and was about $3 \%$ denser than the upper fluid. The input of the lower layer to a depth of $6 \mathrm{~cm}$ was completed in 2 minutes. The lower layer cooled and crystallized, producing strong convection due to both thermal and compositional effects. After 23 minutes, well before the stage had been reached where overturning could take place due to compositional changes alone (as judged from our previous experiments with similar property differences), we initiated the release of gas to simulate the exsolution of volatiles in magma which has become oversaturated with respect to water due to crystallization. Nitric acid was injected into the lower layer through a series of holes in an inlet pipe placed diagonally across the tank. As discussed further below in the description of the "initial trials", enough $\mathrm{K}_{2} \mathrm{CO}_{3}$ had been transported downwards from the very concentrated upper layer during the initial input of $\mathrm{KNO}_{3}$ for it to react with the acid and generate a copious release of $\mathrm{CO}_{2}$ bubbles. These bubbles rapidly reduced the density at the bottom of the tank and caused convective overturning. This produced mixing throughout the tank, with a further reaction and release of gas, as shown in Fig. 1.

On our laboratory scale the bubbles quickly coalesced and rose in continuous plumes through the interface. This behaviour was also observed when both the reactants were placed in the lower layer and the production of gas was confined to that layer, so it was not an artefact of the later reaction above the interface. The experiments thus do not produce a completely satisfactory model of the slow decrease of density due to suspended bubbles, though they do undoubtedly demonstrate how gas release in the lower layer can have a strong destabilizing effect and lead to overturning. 


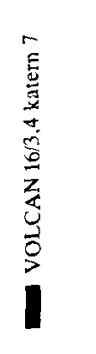



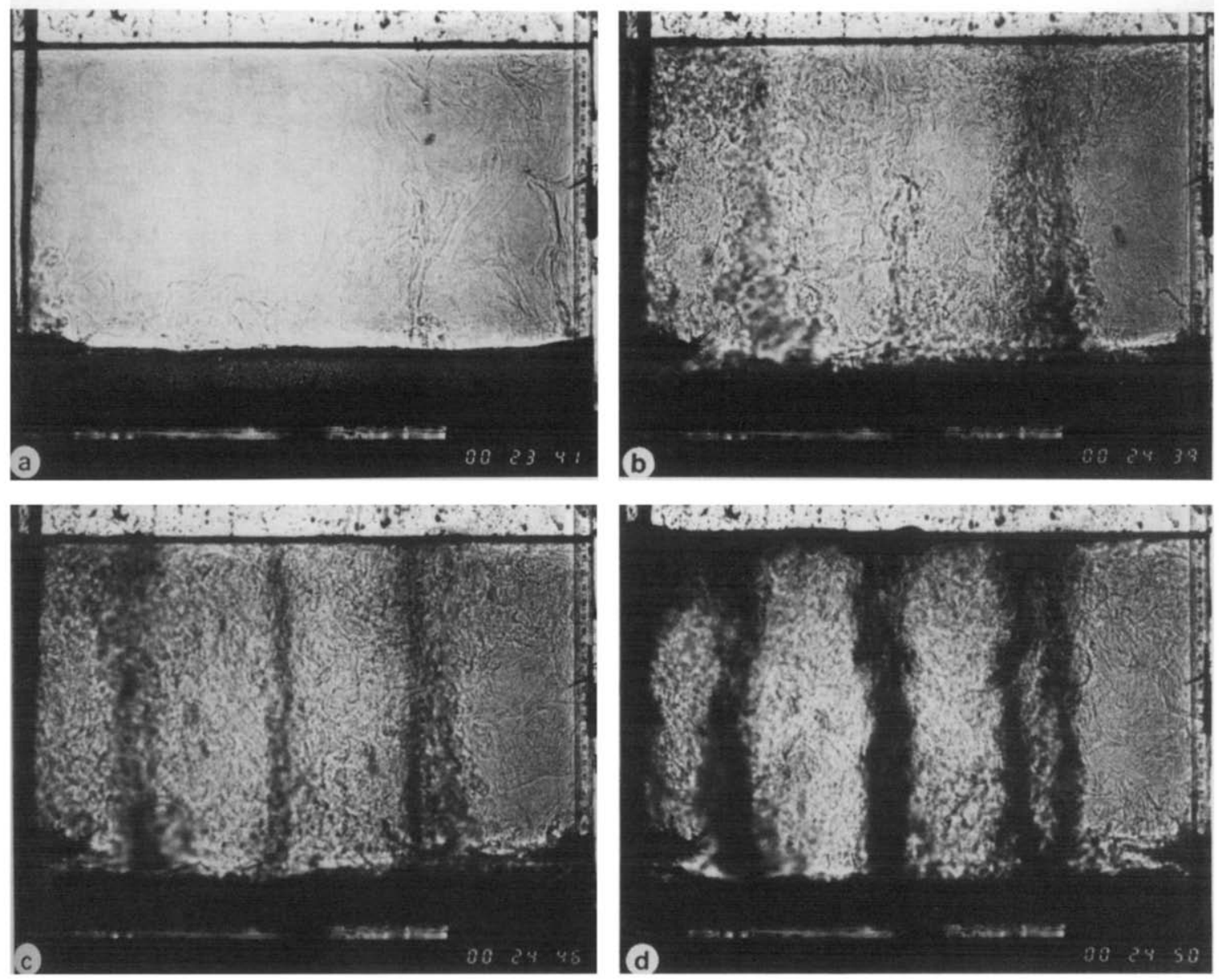

Fig. 1. Sequence of photographs showing the overturning of a two-layer system due to the formation of gas bubbles in the lower layer. The upper layer was a $\mathrm{K}_{2} \mathrm{CO}_{3}$ solution, cooled by bubbling $\mathrm{CO}_{2}$ through it, $T=12.3^{\circ} \mathrm{C}$ just before the input of the lower fluid, specific gravity 1.237 , depth $20.1 \mathrm{~cm}$. The lower layer was a $\mathrm{KNO}_{3}$ solution, input temperature $\approx 50^{\circ} \mathrm{C}$, specific gravity 1.267 , depth $5.6 \mathrm{~cm}$. Crystallization proceeded and caused strong convection in the lower layer. At 23 minutes, before the density of the lower layer had decreased sufficiently to produce overturning, the addition of $\mathrm{HNO}_{3}$ was begun through holes in a pipe extending across the bottom of the tank. The resulting reaction and release of gas led to rapid overturning and mixing. Time is indicated on the clock in hours, minutes and seconds since the initiation of the lower layer. 

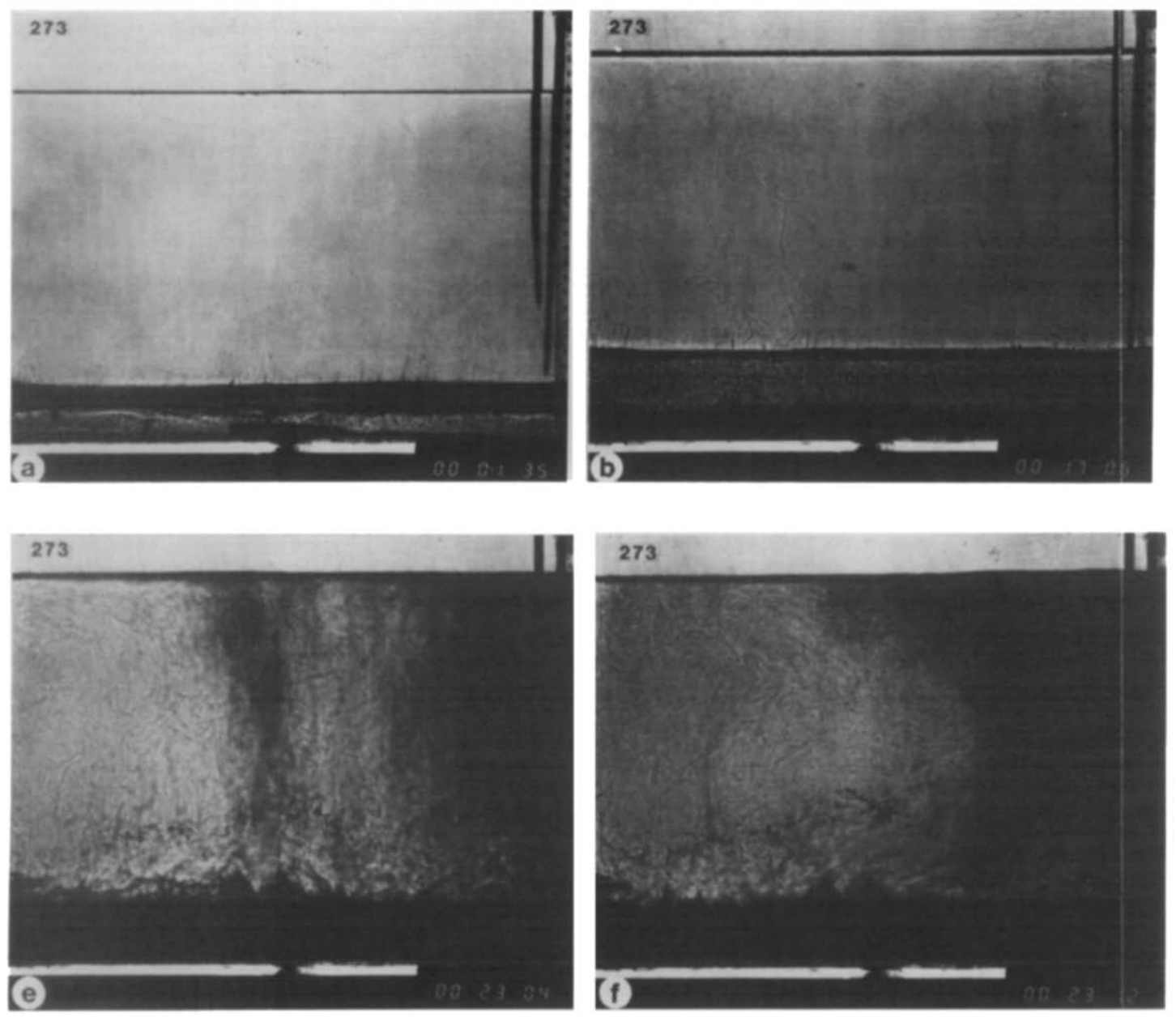

Fig. 2. Sequence of shadowgraph pictures of an experiment of the second series, as described in the text. a. Part way through the filling process, showing the dyed transition region and the bleached lower layer. Upper layer: $\mathrm{NaNO}_{3}+\mathrm{Na}_{2} \mathrm{CO}_{3}+\mathrm{CO}_{2}, T=11^{\circ} \mathrm{C}$, specific gravity 1.268 ; transition layer: $\mathrm{KNO}_{3}, T \approx 55^{\circ} \mathrm{C}$, specific gracity 1.299 ; lower layer: $\mathrm{KNO}_{3}+\mathrm{HNO}_{3}, T \approx 55^{\circ} \mathrm{C}$, specific gravity in excess of 1.299 .

b. The stage where thermal transport alone is important, with crystals of $\mathrm{KNO}_{3}$ growing in the lower layer and little transfer of chemical properties across the interface. Upper layer: $\mathrm{NaNO}_{3}+\mathrm{Na}_{2} \mathrm{CO}_{3}+\mathrm{CO}_{2}, T=14.5^{\circ} \mathrm{C}$; lower layer: $\mathrm{KNO}_{3}+\mathrm{HNO}_{3}, T=41^{\circ} \mathrm{C}$.

c. The start of the breakdown, with streamers of the lower fluid being pulled across the interface. Upper layer: $\mathrm{NaNO}_{3}+\mathrm{Na}_{2} \mathrm{CO}_{3}+\mathrm{CO}_{2}, \mathrm{~T}=17^{\circ} \mathrm{C}$; lower layer: $\mathrm{KNO}_{3}+\mathrm{HNO}_{3}$, $T=33^{\circ} \mathrm{C}$. Specific gravity of the two layers approximately equal at 1.270 .

$\mathrm{d}-\mathrm{g}$. Rapid overturning and mixing of all the components (mixed temperature $20.8^{\circ} \mathrm{C}$ ).

This produces $\mathrm{CO}_{2}$ at an increasing rate, thus adding to the vigour of the convection. h. Bubbling continues (at constant temperature) as acid is drawn out of the layer of crystals, which are at the same time dissolving. 
pp. $269-270$

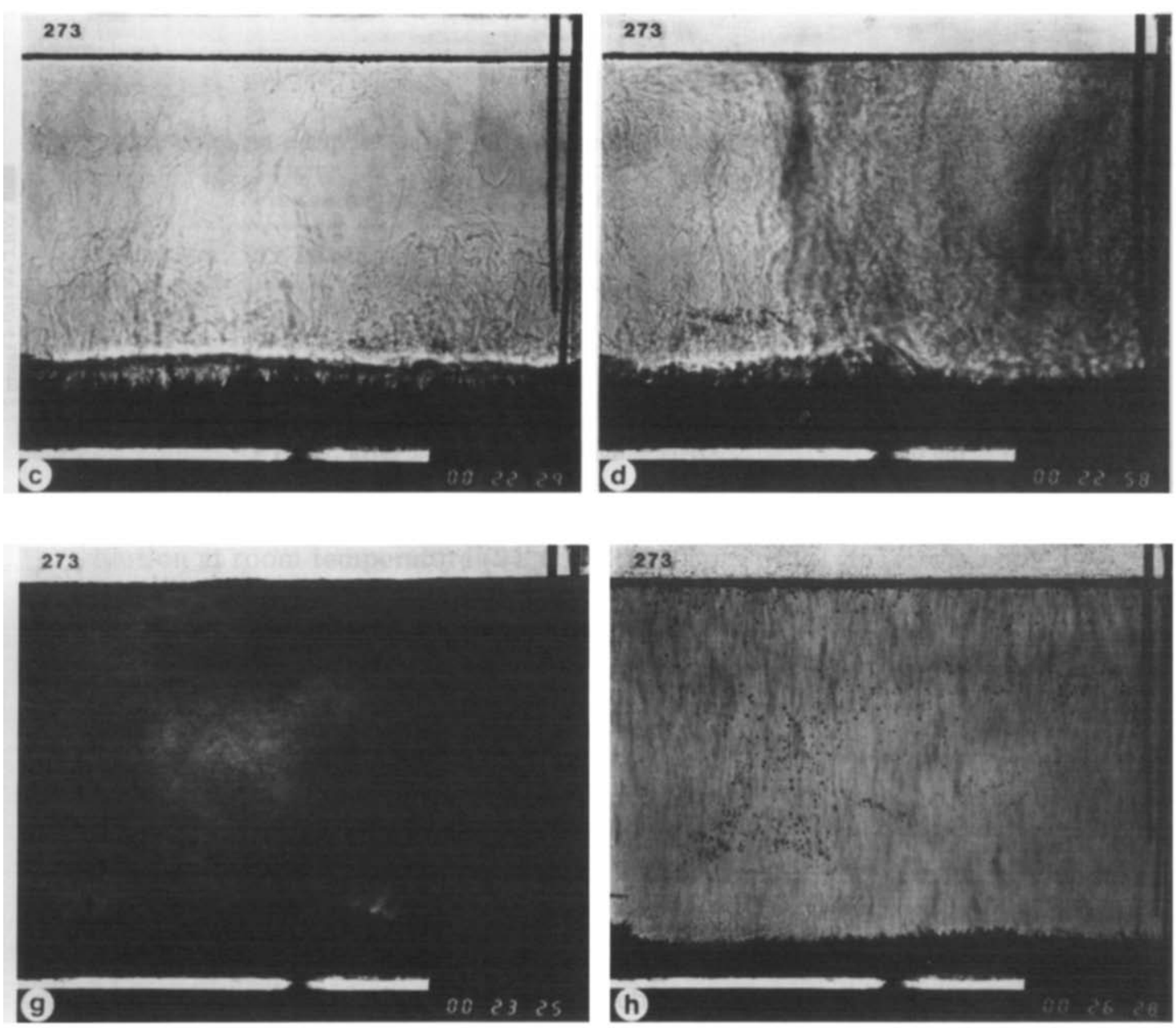


The "bubble plumes" streaming through the interface also had another effect which will be described here because of its possible geological significance. When a small amount of $\mathrm{HNO}_{3}$ was added to the lower layer and the period of gas release was shorter than that needed for complete overturning, the lower fluid was at first drawn upwards, and began to mix with the upper layer. If the production of bubbles ceased at this stage, the still denser fluid fell back and formed a thick gradient region, which replaced the original sharp interface. This seems to be a very effective mechanism for establishing density and property gradients from two well-mixed layers.

In the second series of experiments, undertaken to investigate the effects of mixing and further volatile release after the breakdown of the interface between the two layers, the upper layer, $20 \mathrm{~cm}$ deep, was an aqueous solution of $\mathrm{NaNO}_{3}$ and $\mathrm{Na}_{2} \mathrm{CO}_{3}$, as indicated in Table I. We chose $\mathrm{NaNO}_{3}$ as a solute because its presence increased the density of the upper layer, but it does not react with $\mathrm{HNO}_{3}$. The importance of the lack of reaction will be discussed below when describing the initial trials. This solution was filtered and cooled to $11^{\circ} \mathrm{C}$ by bubbling $\mathrm{CO}_{2}$ through it as before, to produce a specific gravity of 1.268. The lower layer was a dyed aqueous solution of $\mathrm{KNO}_{3}$ heated to $55^{\circ} \mathrm{C}$ before injection, at which temperature the specific gravity was 1.299 . The input was started, and after about $2 \mathrm{~cm}$ of fluid had been introduced below the upper layer, $300 \mathrm{~cm}^{3}$ of $70 \% \mathrm{HNO}_{3}$ was rapidly mixed into the input reservoir, and filling continued until the depth of the lower layer was $6 \mathrm{~cm}$. The total input time was $2 \frac{1 / 2}{2}$ minutes. This procedure was adopted (after some initial trials which are described later) to avoid too much mixing and a reaction produced directly by turbulence during the input. The acid changed the colour of the dye from blue to a pale yellow. Initially there was a blue buffer layer in the middle, which is evident in Fig. 2a, but turbulent mixing from below eliminated this after about 8 minutes and sharpened the interface.

The lower layer began to cool rapidly by transfer of heat through the interface to the upper layer, which was correspondingly warmed. Strong thermal convection occurred in both layers, as indicated both by the fluctuations on the temperature records reproduced in Fig. 3, and directly in the shadowgraph photographs of Fig. 2. Crystals of $\mathrm{KNO}_{3}$ began to form both in the interfacial region and directly on the bottom after about 4 minutes, and strong compositionally-driven convection above them increased the vigour of the mixing in the lower layer. While the lower thermistor was in the transition layer, during which time crystals were growing very near it, the temperature decreased quite rapidly. When the interface sharpened, these crystals fell to the bottom, the temperature rose again briefly, then continued to fall more steadily. Note that at this stage the behaviour was almost indistinguishable from that of the experiments reported previously by Huppert and Turner (1981) or of those which constituted the first series reported in this paper. The rate of transport of all the dissolved components, including the reactants, was so slow compared to heat that no gas was released in either layer.

As the density of the lower layer approached that of the upper as a result 


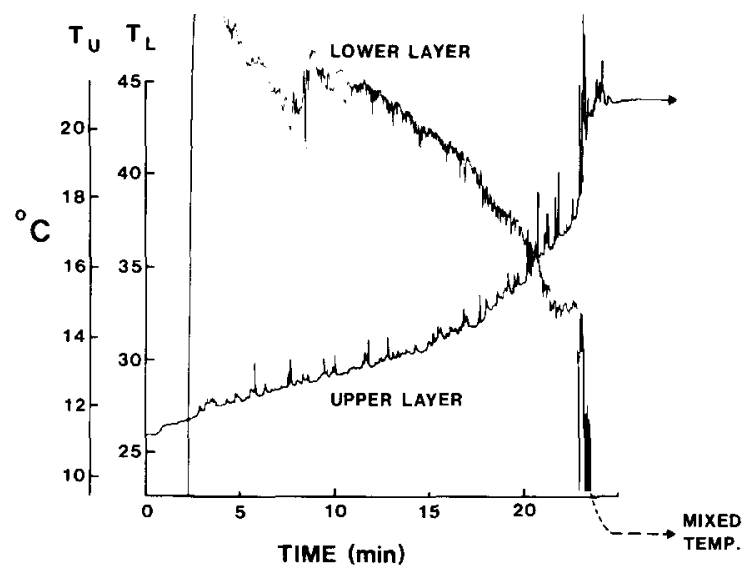

Fig. 3. Reproduction of the chart recording of temperatures measured by thermistors in the two-layer experiment depicted in Fig. 2. Note the gradual change in temperatures due to the heat transfer across the interface, followed by a sudden drop in the temperature of the lower layer. (The lower thermistor went off scale, but the final temperature of the mixed fluid has been added to the plot using the other record.)

of crystallization, the interface became irregular on a small scale, and the activity of the convection increased. Whisps of lower fluid were at first pulled across the interface, and a small amount of gas was released by the resulting reaction. The interface then broke down completely, and the liquid in the lower layer rose into the upper. (See the sequence of photographs in Fig. 2.) Within less than a minute, the temperature at the lower thermistor fell by $10^{\circ} \mathrm{C}$ as the cold upper layer fluid mixed into the lower layer. At the same time the temperature at the upper thermistor rose briefly as the lower fluid poured past it, then it settled back to a constant value, without fluctuations. Simultaneously with the overturning, we observed the new phenomenon: the copious release of $\mathrm{CO}_{2}$ produced by the reaction between $\mathrm{Na}_{2} \mathrm{CO}_{3}$ and $\mathrm{HNO}_{3}$, and facilitated by the prior solution of $\mathrm{CO}_{2}$ in the upper layer. This gas contributed greatly to the convection and was responsible for making the fluid mix ture homogeneous much more rapidly than in the experiments reported by Huppert and Turner (1981). Gas release continued for some hours, at a decreasing rate, as the reaction continued in the interstices of the crystal layer on the bottom. At the same time, the crystals dissolved into the now under-saturated $\mathrm{KNO}_{3}$ solution and left a density-stratified fluid layer at the bottom of the tank. After a day, they had nearly all dissolved, as is consistent with the idea that no crystallization would have taken place at all if the two layers had been initially mixed together and allowed to come to complete equilibrium. The reaction, and release of $\mathrm{CO}_{2}$, would of course still have occurred during this mixing process.

A further variant of this experiment, which perhaps takes one further step towards modelling an explosive eruption, is worth reporting briefly. We con- 
ducted an experiment under conditions similar to those shown in Fig. 2, but with the top of the tank closed by a domed lid, having just a small vent at the top. When overturning occurred and $\mathrm{CO}_{2}$ was released, the fluid-gas mixture was forcibly ejected by the build up of pressure, as shown in Fig. 4. A particularly successful cine film was made of this "eruption".

The reasons behind some of the procedures adopted in the second series of experiments may be made clearer by describing some earlier runs, the results of which also demonstrate the importance of gas release in producing overturning. The conditions of these early runs appear under the heading of "initial trials" in Table I. The upper-layer fluid was a $\mathrm{K}_{2} \mathrm{CO}_{3}$ solution, with specific gravity about $2 \%$ less than that of the lower layer, which was made up of $\mathrm{KNO}_{3}$ plus a little $\mathrm{HNO}_{3}$. As the latter was injected at the bottom of the experimental tank, enough mixing took place with the very concentrated $\mathrm{K}_{2} \mathrm{CO}_{3}$ for this to react with all the acid, so producing an immediate, copious release of gas and overturning. Even when the acid was added after the input had been started (to minimize the effect of turbulence due to the input flow itself), premature gas release and overturning still occurred, because the high concentration of the upper reactant increased the diffusive transfer across the interface. With the lower concentration of reactant plus a non-reactive solute $\left(\mathrm{NaNO}_{3}\right)$ used in the experiments described in detail, and pictured in Fig. 2, the release of gas was delayed until the interface broke down and complete mixing took place, thus giving a more satisfactory analogue of the gas release which follows the overturning and mixing.

\section{DISCUSSION}

Both the experiments described here and the earlier ones reported by Huppert and Turner (1981) investigated the evolution of a layer of hot, heavy fluid injected into the base of a chamber containing cooler, less dense fluid of a different composition. This situation is considered to be common in magmatic systems in which higher temperature mafic magmas are denser than lower temperature differentiated magmas. The formation of separate layers during replenishment is thus a fundamental feature which would occur in any system with the same basic relationships between temperature, composition and density.

An important difference from the experiments described previously is that the two layers in the present experiments contain two highly reactive chemical components. However, while the two layers were able to transfer heat rapidly across the interface separating them, the new experiments again showed that there was only a very slow mass transfer between the convecting layers. That this is markedly different from what would happen if the two layers were assumed to mix initially is shown most dramatically by the second series of experiments, where the highly reactive $\mathrm{HNO}_{3}$ and $\mathrm{Na}_{2} \mathrm{CO}_{3}$ are kept apart by a thin fluid interface. In the case of a magma chamber, this lack of material exchange between two different magma layers implies that the 

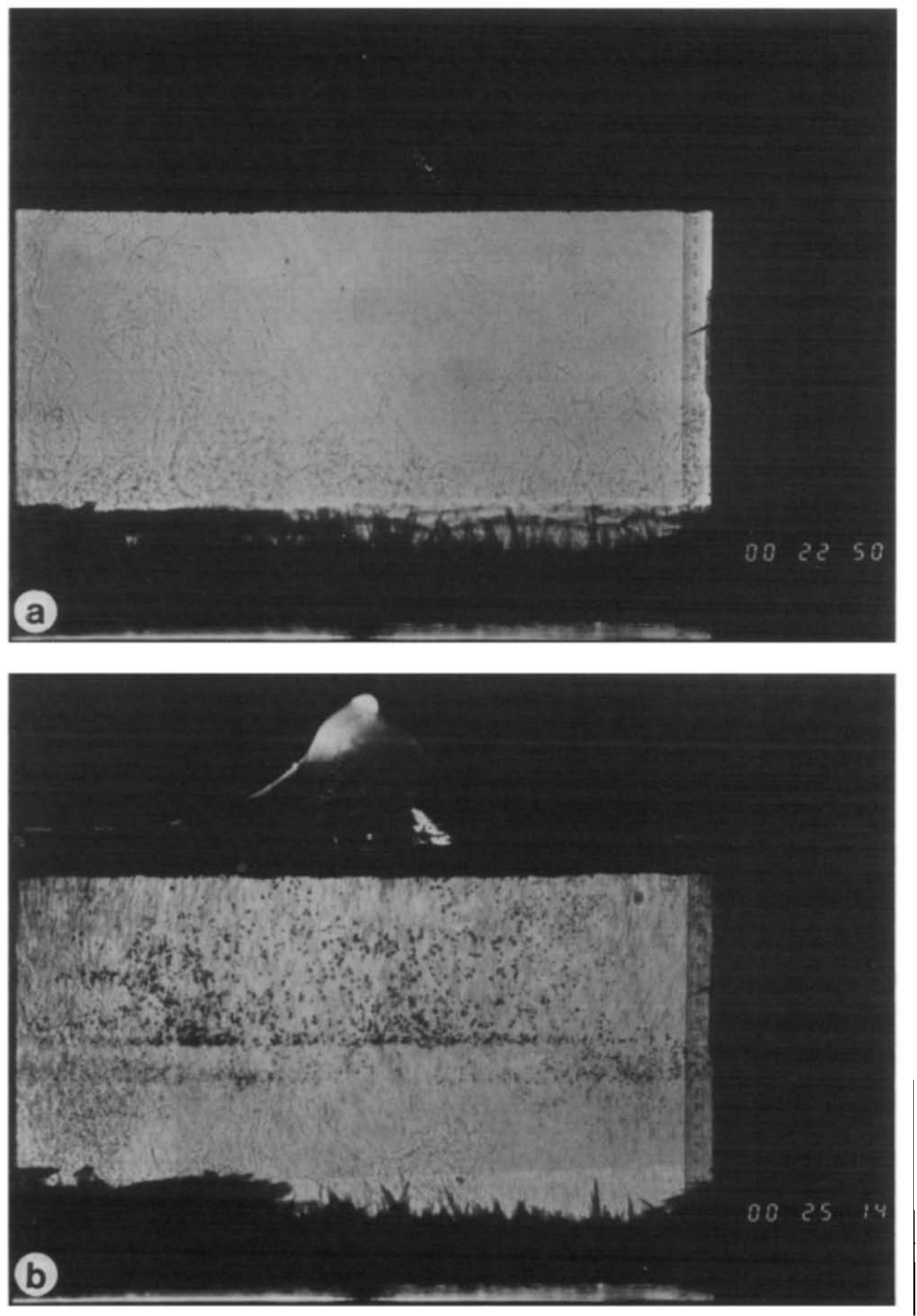
chemical evolution in each magma layer can be distinct and that, until they mix, the magmas behave as chemically independent systems. In particular, they may evolve in chemically different ways, produce quite different crystals and have quite discrete isotopic or trace-element characteristics. Many volcanoes are known to have erupted repeatedly, with alternation of high-temperature mafic and lower-temperature silicic magmas. Our experiments show that there is no need to invoke separate storage systems for the magma types, but that they can co-exist in the same chamber with little or no significant chemical interaction. Magma layers will always come to thermal equilibrium long before significant chemical transports can occur.

The experiments go some way towards confirming the model proposed by Huppert et al. (1982). The fundamental idea is that a layer of dense magma emplaced at the base of a magma chamber can become lighter than overlying magma due to volatile exsolution resulting from crystallization and volatile saturation. The first series of experiments described have modelled this process and shown it to be possible. Overturning in a two-layer system in either a natural or laboratory situation could not occur if the lower layer remained completely gas free. However, as calculated by Huppert et al. (1982) for a natural system, a relatively small volume of gas bubbles can reduce the bulk density of the lower layer considerably. For example, at a pressure of $0.5 \mathrm{kbar}$, in a basalt with a water content of $2 \%$ by weight, the bulk density can be reduced from $2.53 \mathrm{~g} / \mathrm{cm}^{3}$ at $1100^{\circ} \mathrm{C}$ to $2.30 \mathrm{~g} / \mathrm{cm}^{3}$ at $1000^{\circ} \mathrm{C}$ as the magma cools, crystallizes and exsolves some of the water. It is the bulk density of the magma, due to the combination of crystals, fluid and gas which is relevant in this situation because the tendency for crystals to sink or bubbles to rise through the layer is overwhelmed by the much larger turbulent fluid velocities associated with the convective heat transfer between the layers. Thus the bubbles and the crystals can be kept in suspension, regardless of the rate of volatile exsolution, until the bulk density of the lower layer becomes equal to that of the upper layer. Our first series of experiments showed that the evolution of gas in a stable layer can indeed cause overturning and mixing to occur before it would do so due to crystallization alone, and although the detailed manner in which gas was released is different from that in a magma chamber, this difference is dynamically unimportant.

Fig. 4. Experiment in which a domed lid, with only a small vent at the top, was added to the tank. The initial conditions were very similar to those described in the caption to Fig. 2 . a. The state just before breakdown of the interface, when very little gas had been released b. Following overturning and mixing, when $\mathrm{CO}_{2}$ was being released vigorously. The fluidgas mixture was forcibly ejected from the vent by the build up of pressure. The gas bubbles were brightly illuminated at this stage by a beam of light shone through the dome from the side. 
Following overturning, the thorough mixing of the reactive components in our experiments initiated violent volatile release. A similar situation could occur when volatile-rich mafic magma is mixed with more differentiated magma. The intimate dispersion of mafic magma through the whole of the upper layer would promote a rapid transfer of heat, with further crystallization and release of volatiles. In addition, the volatiles would, on average, be at a lower pressure resulting in either expansion or increased chamber pressure. These effects could aid the eruptive process as discussed by Sparks et al. (1977). More fundamentally, however, the mixing of magmas in this way would allow many other sorts of reactions to occur, for example between phenocrysts and surrounding liquid.

While the ideas of Huppert et al. (1982) were applied by them to the release of $\mathrm{H}_{2} \mathrm{O}$ from calcalkaline magmas, the mechanism might also be effective in $\mathrm{CO}_{2}$-bearing alkaline mafic magmas. $\mathrm{CO}_{2}$ is poorly soluble in mafic magmas at low pressures and we suggest that the processes outlined by Huppert et al. (1982) and in this paper could also be applicable to silica undersaturated $\mathrm{CO}_{2}$-bearing magmatic systems.

We can summarize our general conclusions as follows. The behaviour of our simple experimental systems was dominated by compositional changes due to crystallization and phase changes, in this case the liberation of gas. In addition, the formation of two separate layers at the beginning of the experiment is due to the multidiffusive, multicomponent properties of the system. Features such as layering and the chemical isolation of the layers are fundamental to such systems. We thus argue that magmas which, in these respects, are just more complex systems of a similar kind, will likewise be dominated in their behaviour by the same sorts of physical and dynamical processes.

\section{ACKNOWLEDGEMENTS}

We are grateful to Derek Corrigan and Ross Wylde-Browne for their invaluable assistance at every stage of the experimental work reported here, and to Brian Baker, Alex McBirney and Bruce Marsh for very helpful comments on a previous draft of the manuscript. The paper is contribution No. 229 from the Department of Earth Sciences, Cambridge.

\section{REFERENCES}

Anderson, A.T., 1976. Magma mixing: petrological process and volcanological tool. J. Volcanol. Geotherm. Res., 1:3-33.

Eichelberger, J.C., 1980. Vesiculation of mafic magma during replenishment of silicic magma reservoirs. Nature, 288: 446-450.

Huppert, H.E. and Sparks, R.S.J., 1980a. Restrictions on the compositions of mid-ocean ridge basalts: a fluid dynamical investigation. Nature, $286: 46-48$. 
Huppert, H.E. and Sparks, R.S.J., 1980b. The fluid dynamics of a basaltic magma chamber replenished by influx of hot, dense ultrabasic magma. Contrib. Mineral. Petrol., 75: 279-289.

Huppert, H.E. and Turner, J.S., 1981. A laboratory model of a replenished magma chamber. Earth Planet. Sci. Lett., 54: 144-152.

Huppert, H.E. Sparks, R.S.J. and Turner, J.S., 1982. The effects of volatiles on mixing in calcalkaline magma systems. Nature, 297: 554-557.

McBirney, A.R. and Noyes, R.M., 1979. Crystallization and layering of the Skaergaard intrusion. J. Petrol., 20: 487-554.

Sparks, R.S.J., Sigurdsson, H. and Wilson, L., 1977. Magma mixing: a mechanism for triggering acid explosive eruptions. Nature, 267: 315-318.

Sparks, R.S.J., Meyer, P. and Sigurdsson, H., 1980. Density variation amongst mid-ocean ridge basalts: implications for magma mixing and the scarcity of primitive magmas. Earth Planet. Sci. Lett., 46: 419-430. 